\title{
JUVENTUDE E REINSERÇÃO ESCOLAR: SIGNIFICADOS SOBRE O SER JOVEM
}

\author{
Vanessa Petró*
}

Resumo: O estudo analisa as representações que os estudantes da Educação de Jovens e Adultos (EJA) possuem sobre o que é ser jovem e como estar nessa modalidade de ensino contribui para isso. Essa análise subsidia a compreensão do fenômeno da juvenilização da EJA. São discutidos dados empíricos oriundos de pesquisa quantiqualitativa que apontam para a presença significativa de jovens na EJA/Ensino Médio nas escolas de Porto Alegre, e indica-se o porquê desses jovens estarem na EJA. Os dados são aprofundados com a análise da trajetória de estudantes da EJA. Discute-se o que significa ser jovem e estar cursando a EJA e as percepções dos jovens sobre esse momento da vida. Retomar os estudos remete a um sentimento de percursos em construção, o que é associado pelos estudantes da EJA como uma característica da juventude.

Palavras-chave: Juventude, escolarização, Educação de Jovens e Adultos, Ensino Médio

\section{Apresentação}

A Educação de Jovens e Adultos (EJA) é uma modalidade de ensino que tem como objetivo garantir o direito à Educação Básica aos jovens e adultos que, pelos mais diferentes motivos, não conseguiram ingressar ou permanecer na escola. A expansão do Ensino Médio no Brasil ampliou os perfis de jovens a alcançarem esse nível de ensino, mas não significa ainda que todos eles consigam concluir a Educação Básica, pois muitos jovens abandonam a escola.

Os estudantes que estão matriculados na EJA, significativamente jovens e de classes populares, possuem trajetórias escolares descontínuas, marcadas pelo insucesso escolar, que, pela dificuldade de visualizar perspectivas na escola, abandonaram-na e mais tarde se viram diante da necessidade de aumentar o nível da escolarização e voltaram a buscar na escola um diploma, aprendizagens e novas sociabilidades.

Estudos apontam para um processo denominado como "juvenilização" da EJA (BRUNEL, 2001; CARRANO, 2007), isto é, a presença de jovens que teriam ainda

\footnotetext{
* Professora do Instituto Federal de Educação, Ciência e Tecnologia do Rio Grande do Sul (IFRS/Campus Feliz), doutora em Sociologia pela UFRGS. A pesquisa contou com financiamento da CAPES.
} 
perfil para cursar o ensino regular de nível fundamental ou médio, mas estão frequentando a EJA. A presença do público jovem na EJA deve-se à associação de fatores como a necessidade de certificação para o mundo do trabalho e a defasagem idade série. Associado a isso ainda há o aspecto legal, que define como idade mínima de quinze anos para frequentar o Ensino Fundamental e dezoito anos para o Ensino Médio e também para a realização de exames de certificação (DI PIERO, 2005).

A discussão sobre a juvenilização da EJA requer um olhar que permita compreender o que significa ser jovem e estar nessa modalidade de ensino, considerando que o entendimento dessa categoria não se esgota no atributo idade. Para responder a essa questão, é necessário perguntar por que esse estudante não se "enquadra" no modelo regular do Ensino Fundamental ou Médio. Estar-se-ia diante de um estudante, por um lado, "velho" demais para cursar a educação regular e, por outro lado, “jovem” demais para cursar a EJA? Que implicações essa modalidade de ensino exerce sobre o conceber-se como jovem? Como compreender a categoria juventude tendo em vista a maleabilidade no processo de escolarização e os desafios postos à questão da idade na EJA, na qual os tensionamentos sobre as fronteiras dessa categoria estão em evidência? Essas são algumas das questões discutidas ao longo desse artigo.

\section{Juventude: uma categoria sociológica}

O surgimento da categoria sociológica juventude está associado à modernidade, que desencadeou mudanças sociais, culturais e econômicas; uma maior diferenciação social e autonomia das instituições; uma crescente racionalização, burocratização e secularização da vida e alterações nas relações de confiança e tempo-espaço (GIDDENS, 1991).

Com as transformações ocorridas na organização familiar (século XVII), a família volta-se mais para si, organizando-se em torno da criança e construindo uma delimitação mais clara e privada em relação à sociedade. Nessa nova organização, a juventude assume um papel social diferente, pois a preparação das condições de existência dos filhos passa a ser função dos pais (ARIÈS, 1981).

O surgimento da juventude como fenômeno social moderno fez com que a educação familiar fosse substituída pela educação escolar, o que conferiu um lugar de destaque ao jovem. À medida que a escolarização passou a ocupar um espaço maior 
para a inserção no mundo do trabalho, a fase entre a infância e a vida adulta passou a ser cada vez mais visível (PAPPÁMIKAIL, 2011).

$\mathrm{O}$ aspecto econômico tem um papel importante nesse processo, pois foi a partir de mudanças profundas nessa área que emergiu um domínio educativo (PAPPÁMIKAIL, 2011). A escola passa a ser o único território legítimo para a vivência de grande parte da juventude, sendo o espaço próprio para os jovens que se encontram em uma etapa não produtiva do ciclo de vida.

Se a modernidade permite o surgimento de uma nova fase da vida - a juventude -, a modernidade tardia reconfigura as formas de definição dessa categoria da mesma maneira que altera também a forma de atuação dos jovens na sociedade em decorrência das reconfigurações, por exemplo, relacionadas à escolarização, às descontinuidades profissionais e à organização familiar. A modernidade tardia caracteriza-se como um processo de mudanças contínuas que conduzem a transformações nas bases da sociedade ocidental. As transformações constantes da realidade colocam os indivíduos diante de incertezas (GIDDENS, 1991).

A definição da categoria sociológica juventude é um grande desafio, considerando as diferentes dimensões do conceito. Bourdieu (2003) já alertava que as classificações a partir da idade são arbitrárias. Isto é, categorias como juventude são construídas socialmente a partir das lutas estabelecidas e assumem significados distintos de acordo com o contexto ou com a cultura.

Segundo Pais (1990), a ideia de uma cultura juvenil unitária é redutora da realidade, pois, sob o rótulo de uma mesma juventude, estão grupos ideológicos, profissionais e classes sociais muito diferentes. À ideia de culturas juvenis está associado um conjunto de valores, crenças, símbolos e práticas que podem ser inerentes a uma fase da vida ou compor práticas assimiladas das gerações anteriores ou das trajetórias de classe.

Uma análise sociológica que pretenda considerar a juventude simplesmente pela questão etária é limitada. A juventude como condição social carrega consigo um tipo de representação (PERALVA, 1997). Assim, é possível entendê-la à medida que é colocada em comparação com outra etapa da vida - através do aspecto relacional.

A trajetória de vida tem a passagem de uma fase para a outra assinalada por "marcadores de passagem" definidos de acordo com a organização de cada grupo social (FERREIRA; NUNES, 2010). Estão entre os mais comuns a escolarização, a 
autonomização em relação à família de origem, a constituição da própria família, o ingresso no mercado de trabalho, a aposentadoria, o nascimento dos filhos e/ou netos, dentre outros. Assim, a transição para a vida adulta não pode se limitar à relação escolatrabalho, mas à análise da emergência de novos estilos de vida e das diferentes formas de ingressar na vida adulta (CAMARANO; MELLO, 2006).

Não se pode imaginar que exista uma rígida linearidade nessas situações definidas como transitórias. Muitos adolescentes têm seus filhos prematuramente, constituem família e iniciam-se no mercado de trabalho cedo, enquanto outros permanecem muito mais tempo na casa dos pais, prolongam a vida escolar, retardam a iniciação profissional, etc.

No âmbito desse artigo utilizam-se outros aspectos além do biológico para compreender a juventude, concordando com perspectivas que relativizam esse aspecto, como é o exemplo de Vandenberghe (2014) quando coloca de lado a perspectiva etária e destaca a identificação dos indivíduos com determinada fase da vida. Concebe-se, nesse artigo, a categoria juventude de forma relacional, sobretudo a partir do momento em que o conceito de juventude articula-se diretamente com o contexto da EJA.

\section{Procedimentos metodológicos}

A pesquisa que embasou a produção desse artigo é de caráter quanti-qualitativo e teve como foco de investigação os jovens que cursavam o Ensino Médio na modalidade EJA, em Porto Alegre, no ano de 2012, considerando todas as redes de ensino presencial que possuíam turmas de nível médio (federal, estadual e particular). A escolha por jovens do Ensino Médio decorre do fato de que, nesse nível de ensino, estão concentrados grandes desafios relacionados à permanência na escola, o que é resultante, muitas vezes, da necessidade de os jovens trabalharem, do desinteresse pela escola, de uma inadaptação do currículo em relação aos interesses dos jovens e do alcance da maioridade, o que desobriga o jovem de frequentar a escola (DAYRELL, 2014).

Em um primeiro momento, foram coletados dados quantitativos com vistas à identificação do perfil dos estudantes da EJA/ Ensino Médio em Porto Alegre, o que foi feito por meio da aplicação de um questionário estruturado, respondido por uma amostra composta por aproximadamente $10 \%$ dos estudantes da EJA/Ensino Médio em Porto Alegre no ano de 2012, totalizando 447 questionários aplicados em 10 escolas diferentes. O Censo Escolar do referido ano indicou a existência de 4.715 estudantes 
matriculados na EJA/Ensino Médio em Porto Alegre. Para a amostragem selecionada dessa população a margem de erro foi $4,4 \%$, enquanto o nível de confiança foi de $95 \%$.

A partir do questionário aplicado foi possível traçar um perfil dos estudantes da EJA, destacando os atributos dos participantes da amostra, a situação ocupacional e econômica do aluno e da família, a trajetória escolar e a relação com a EJA. A partir da aplicação, tabulação e análise dos questionários respondidos e da identificação de perfis de estudantes, passou-se para a fase qualitativa, com a realização das entrevistas com os jovens alunos da EJA de nível médio. O critério inicial para a seleção dos estudantes era ter idade compreendida entre 18 e 29 anos, uma vez que o enfoque da pesquisa era o público jovem da EJA/Ensino Médio. A partir do critério idade foi considerada a diversidade existente em relação aos atributos dos jovens, especialmente o sexo e os aspectos próprios do percurso escolar, tais como reprovação e interrupção dos estudos.

No total, foram entrevistados quinze estudantes da EJA, sete homens e oito mulheres, distribuídos por diferentes escolas. Embora fosse apontada a faixa etária estabelecida, foi entrevistado um jovem de dezessete anos.

\section{Perfil dos estudantes: a EJA está cada vez mais jovem?}

A EJA no nível médio em Porto Alegre, segundo o estudo empírico realizado, é constituída em sua maioria por um público jovem, pois $62,2 \%$ dos matriculados nessa modalidade em 2012 tinham entre 18 e 29 anos. Além disso, chama atenção o fato de $8,1 \%$ dos estudantes desse nível de ensino terem menos de 18 anos. A idade mínima para ingressar no Ensino Médio na modalidade EJA é 18 anos. Entretanto, através de recursos judiciais, alguns estudantes conseguem autorização para cursar a EJA por serem emancipados ou porque desenvolvem algum tipo de trabalho que os impede de frequentar o Ensino Médio regular, como é o caso de alguns meninos que estão ingressando na carreira esportiva. A faixa dos 30 anos ou mais somou 25,3\% dos entrevistados.

A distribuição dos entrevistados por sexo apresentou-se equilibrada: 50,6\% são homens e 49,4\% mulheres. Entretanto, chamou atenção a distribuição de sexo conforme a faixa etária. Na faixa etária com maior incidência de estudantes jovens (entre 18 e 20 anos) havia mais homens (46\%) e menos mulheres (26,2\%). Nas faixas etárias mais altas, tinha maior porcentagem de mulheres, por exemplo, entre 26 e 40 anos havia $2,7 \%$ de homens e $10 \%$ de mulheres. Na faixa dos 41 anos ou mais o mesmo se repete: 
4,0\% de homens e 15,0\% de mulheres. Uma das explicações para isso pode estar associada ao abandono escolar das adolescentes, que, por causa da gravidez, deixam a escola nessa fase e, quando retomam os estudos, fazem-no mais tarde.

O fato de a maioria dos entrevistados ser jovem se refletiu em outros atributos identificados no público entrevistado: a maioria é solteira $(69,4 \%)$ e não tem filhos $(66 \%)$. Os estudantes que informaram ter filhos estão entre as faixas etárias mais elevadas. Apenas $14,8 \%$ dos estudantes não tinham renda individual; $47 \%$ possuíam trabalho formal e somente $4,3 \%$ eram inativos. A renda dos estudantes é baixa. A maioria dos entrevistados tinha renda individual de até três salários mínimos $(50,1 \%)$ e a renda mensal familiar também era de até três salários mínimos $(33,6 \%)$, o que inclusive pode ser indicativo de que a renda familiar é a dos próprios estudantes. Em segundo lugar, está o grupo que possuía renda mensal familiar entre três e cinco salários mínimos $(29,8 \%)$.

A maior parte dos entrevistados $(46,6 \%)$ residia com os pais e $25,8 \%$ moravam com o(a) companheiro(a). Em relação às qualificações escolares dos pais há polos de concentração da escolaridade. O primeiro deles é de estudantes cujas mães e pais possuíam Ensino Fundamental incompleto: respectivamente, 32,9\% e 26,4\%. O segundo concentra-se no Ensino Médio incompleto, com 19,7\% de mães e 23,0\% de pais. Isso indicou que as mães possuem escolaridade menor que os pais dos estudantes pesquisados.

O fato de os pais disporem de um capital escolar médio ou baixo não significa que os filhos tenham como destino a reprodução das mesmas condições. Conforme Lahire (1997), essa situação original, em vez de determinar o perfil disposicional dos filhos, pode fazer com que eles sejam os designados a adquirir um novo tipo de capital escolar que permita resolver as limitações da família em relação à escolarização. É nessa linha também que seguem os estudos de Neves (2013) sobre o acesso de estudantes cotistas e bolsistas à universidade, indicando que, muitas vezes, os estudantes contemplados por essas políticas públicas são os primeiros da família a alterarem o quadro de baixo capital escolar que se reproduzia na família e eles passam a atuar como incentivadores para que outras pessoas da família busquem o Ensino Superior. 
Em geral, os estudantes pesquisados concluíram o Ensino Fundamental em escola regular pública de Ensino Fundamental (54,6\%), seguida por escola pública de EJA $(18,3 \%)$ e por escola privada de EJA $(12,8 \%)$.

A descontinuidade escolar é uma característica da modalidade EJA, o que não pode ser entendido como evasão no sentido de abandonar a escola (MILETO, 2009; CARMO, 2010). A repetência escolar é um dos fatores importantes a ser considerado na reflexão sobre a interrupção dos estudos e o ingresso na EJA. Dos estudantes pesquisados, 65,1\% reprovaram durante o Ensino Fundamental.

É significativa a porcentagem de estudantes que interromperam os estudos $(74,50 \%)$, mas os dados coletados indicaram ainda que $22,15 \%$ dos entrevistados nunca interromperam os estudos. Isso decorre da reprovação, que gera a distorção idade-série e, com isso, à medida que os jovens atingem a idade suficiente para migrar de modalidade, fazem-no tendo em vista que a EJA é uma modalidade mais rápida.

O motivo mais recorrente para interromper os estudos está relacionado à questão do trabalho $(33,1 \%)$. A falta de tempo para estudar pode estar relacionada também à necessidade de trabalhar e representou $11,5 \%$ dos motivos para interromper o processo de escolarização.

Embora o trabalho tenha aparecido de forma muito clara na pesquisa quantitativa, as entrevistas evidenciaram que não foi diretamente uma necessidade econômica de trabalhar que fez os estudantes deixarem a escola. Quase todos os estudantes começaram a trabalhar muito cedo, algumas vezes pela vontade de ter seu próprio dinheiro, autonomizar-se em relação aos pais, e isso foi distanciando ainda mais os jovens da escola.

O desinteresse pela escola é um fenômeno que pode ser identificado nas mais diferentes realidades escolares. Há um sentimento de tédio por parte dos jovens em relação às práticas escolares que os mantêm distantes e sem identificar a utilidade da escola. Os jovens geralmente são impacientes com essas práticas, porque não percebem na escola a capacidade de impulsionar transformações nas suas vidas (SARAVÍ, 2009).

O trabalho também é apontado pelos estudantes da EJA como um importante fator que influencia o retorno à escola. Ao serem somadas todas as respostas atribuídas que relacionam o trabalho ao retorno à escola, obtêm-se $22,7 \%$. Distanciando-se desse motivo mais pragmático, foi evidenciado o interesse em aumentar os conhecimentos $(21,0 \%)$. Em seguida, apareceram as motivações que remetem a um planejamento de 
vida e de continuidade dos estudos, tais como fazer faculdade $(18,1 \%)$ e fazer curso profissionalizante $(16,2 \%)$.

As características específicas da EJA foram apontadas como importantes para a escolha da modalidade. Em geral, ela é concebida como um espaço onde o ensino é mais fácil, os horários são flexíveis e é possível concluir o nível de ensino rapidamente. A rapidez para a conclusão do curso foi o que motivou $33,2 \%$ a procurarem a EJA; $23,2 \%$ dos estudantes matricularam-se em decorrência dos horários mais adequados para as aulas e $10,9 \%$ pela proximidade de idade em relação a dos colegas.

\section{Como a EJA age sobre o definir-se como jovem?}

Tradicionalmente, segundo Dayrell (2007), a sala de aula era considerada espaço privilegiado para o ensino e para a aprendizagem, com destaque para a disciplina do corpo e da mente. Mas, segundo o autor, já não se pode mais afirmar isso na atualidade, pois ela emergiu como um espaço repleto de uma "complexa trama de relações de alianças e de conflitos, de imposições de normas e estratégias individuais e coletivas de transgressão, na qual é visível a tensão entre o 'ser jovem' e o 'ser aluno', um e outro ganhando mais visibilidade dependendo do contexto" (DAYRELL, 2007, p. 220).

A escola cada vez mais minimiza a sua importância como uma instituição definidora do que é ser jovem (DAYRELL, 2007), abrindo espaço para a cultura de massas e para as novas tecnologias (PEREIRA, 2016). Entretanto, as narrativas analisadas ao longo dessa pesquisa apontam para o significado assumido pela retomada dos estudos e do "estar na escola" como algo que contribui para a forma como os estudantes se definem no que tange à fase da vida. A EJA contribui para a constituição da imagem dos estudantes enquanto jovens. Quando os estudantes estavam na escola (antes da interrupção dos estudos ou da mudança de modalidade), em muitos casos, tinham um anseio por "ser adulto". A saída da escola e o ingresso no mundo do trabalho, dentre outros fatores, colaboraram para essa imagem de si. Entretanto, ao voltarem para a escola, parece renascer o sentimento de retomada da sua trajetória escolar e nela está presente a ideia de construção do futuro de forma que a "vida adulta" será alcançada quando forem conquistados esses planos. Nesse sentido, estar estudando remete a fazer algo que é próprio da juventude.

A categoria juventude é construída a partir da oposição com as categorias adulto, idoso, adolescente ou criança, que também ocupam determinados espaços nos diferentes 
níveis de ensino. É quando esses distintos grupos se encontram em um mesmo espaço que certos comportamentos vão fazendo com que, de forma relacional, sejam estabelecidos rótulos que classificam os indivíduos como jovens ou adultos.

A EJA é um espaço onde é recorrente o tensionamento sobre o ser jovem e o ser adulto. A modalidade apresenta-se como um lugar para aqueles que já não se enquadram mais no espaço da educação regular, sobretudo pela questão da idade.

É possível apontar para diferentes formas de ser jovem no espaço da EJA. Essas trajetórias plurais não podem ser vistas da mesma forma daqueles que eventualmente possuam um percurso de vida e escolar "mais linear". Dadas essas diferenças é que recorrem à EJA, pois ela possui ou eles imaginam possuir especificidades para atendêlos.

Nas turmas de EJA estão presentes jovens estudantes trabalhadores, muitas vezes cansados das suas rotinas de trabalho, com pouco tempo para realizar as atividades escolares; jovens que já formaram suas famílias; jovens ainda sob a responsabilidade dos pais, enfim, uma multiplicidade de perfis, de comportamentos e de interesses. Entretanto, na escola, alguns desses jovens assumem uma postura característica dos adolescentes, fazendo inclusive com que seus colegas os definam como imaturos. Conforme Bourdieu,

[...] temos um universo de adolescência, no verdadeiro sentido da palavra, quer dizer de irresponsabilidade provisória: estes "jovens" encontram-se numa espécie de terra de ninguém social, são adultos para certas coisas, são crianças para outras, jogam nos dois tabuleiros (BOURDIEU, 2003, p. 154).

As narrativas dos estudantes indicou certo desconforto relacionado à presença dos jovens em algumas turmas. Há escolas que organizam as turmas segmentando-as pela faixa etária dos alunos. Houve uma sinalização, segundo as entrevistas, para o fato de que os jovens ali presentes tiraram o "sossego" até então predominante em uma modalidade de ensino composta por pessoas adultas e conscientes de seus objetivos.

Tem 18 ou 19 anos. Tá ali não sei por quê, falta a aula, vem quando quer, vem só pra bagunçar mesmo. [...] De vez em quando eu me irrito, porque eles estão numa fase de uma coisa do colégio, da rua. Não se interessa pelo que o professor tá explicando. [...] E agora nesse semestre me colocaram pra vicelíder então eu como líder, vice-líder se eu acho que tá atrapalhando eu chamo atenção na boa, conversando e agora tem um menino que parece que faz pra me provocar e aí eu só olho pra ele e ele: tá eu vou parar líder. [...] Aí tem um colega que é bem estouradinho e ele diz: oh, meu, eu tô aqui pra prestar atenção na aula, se tu não tá, sai da sala, vai conversar na rua. (Jovem B, mulher, 24 anos). 
A narrativa da Jovem B elucida uma diferença entre o "colégio" e a EJA, indicando que a postura imatura é característica do "colégio" e que na EJA caberia um comportamento mais maduro. Isso reflete uma ideia de que a EJA seria uma modalidade que comporta estudantes com um comportamento diferente, associado ao dos adultos.

Quando os jovens passaram a ser predominantes em muitas salas de aula, evidenciou-se, muitas vezes, um conflito entre gerações e tornaram-se corriqueiras situações de indisciplina em sala de aula, pois muitos daqueles estudantes com dificuldades de adaptação nas turmas regulares estão matriculados na EJA e essa modalidade nem sempre consegue olhar para as especificidades ali encontradas. Evidencia-se a existência de um comportamento escolar que precisa ser seguido, no qual não cabem conversas, descontração, qualquer coisa que não seja prestar atenção nas aulas. Aqui se discute isso na perspectiva dos próprios estudantes que esperam que os colegas adotem essa postura e quando alguns não o fazem são logo vistos como aqueles que "não querem nada com nada". Isso aponta para um hiato recorrente nos espaços escolares em que as formas de sociabilidades (sobretudo juvenis) não conseguem ser apropriadas pela "estrutura” escolar (PEREIRA, 2016).

Seria equivocado afirmar categoricamente que a relação entre os "jovens" e os "adultos" no interior das salas de aula da EJA se dão de forma dicotômica - harmônica ou conflituosa. O que as narrativas apontam é para formas plurais de convivência. Qualquer um desses polos pode ser encontrado em diferentes momentos e entre os mesmos atores, conforme o contexto que se esboça.

Entre os entrevistados está um jovem de dezessete anos, jogador de futebol. A narrativa do jovem remete a uma dualidade na forma como ele vive o trabalho e a escolarização. O ingresso no mundo do futebol exigiu uma saída precoce de casa, antes mesmo que tivesse vivido a infância e a adolescência, o que aponta para uma trajetória escolar que em alguns momentos não é priorizada, mas é obrigatória por exigência legal. Nesse caso, a EJA visivelmente torna-se uma forma, por um lado, de agilizar esse compromisso e poder concluir o ensino médio rapidamente e, por outro lado, vivenciar um contexto com pessoas mais maduras e que conseguem compreender um pouco melhor a sua realidade, não ficando tão em evidência como ocorria, segundo o Jovem $\mathrm{H}$, quando não cursava essa modalidade e frequentemente era apontado pelos colegas como privilegiado pelos professores, em decorrência da sua profissão. Essa última questão evidencia um componente socioeconômico, porque, segundo o Jovem $\mathrm{H}$ a 
escola regular onde estudava ficava na periferia e os colegas não eram "boas influências" e perseguiam-no pela diferença que ele atribui como sendo de classe social.

A presença de estudantes no Ensino Médio da EJA antes de completarem os dezoito anos contribui para e reflete um processo de aceleração de entrada na juventude. No caso do jovem analisado, complementado por outros aspectos como a profissionalização. Conforme Gouveia e Silva (2015), a redução da idade para ingresso na EJA fez com que adolescentes entre quinze e dezessete anos fossem "juvenilizados". Para as autoras isso remete também à exclusão de uma faixa etária na qual o Estado possui ainda o compromisso de garantir a Educação Básica (regular), ocasionando a aceleração dos estudos.

A inserção do jovem em um contexto com pessoas de diferentes idades também auxilia na definição da fase da vida e a EJA é um lugar que reflete essa realidade. Alguns estudantes fizeram uso do espaço da EJA para identificar características que lhes aproximam da vida adulta por terem contato com pessoas mais velhas e, em decorrência disso, variarem seus assuntos e sua postura de acordo com esse contexto.

\begin{abstract}
Ah, muitos dizem às vezes criança, mas eu me identifico com jovem, mas muitos já me veem como adulto pelo que já me conhecem, os amigos que me conheceram quando eu vim morar aqui em Porto Alegre já me falaram "tu tá mudado, tá diferente, mas ainda continua um brincalhão, uma criança". [...] Pra mim a diferença é, acho que muito porque, como eu te falei, quando eu estudava num colégio que era só de jovens da minha idade, tinha só assuntos bobos, sabe? Só brincadeiras bobas, não tinha uma conversa sadia, tinha palavrões. [...] Ser adulto, por outro lado, por causa da influência, porque eu converso quase com todos meus colegas e a grande maioria dos meus colegas aqui no colégio tem uma vida, tem um jeito e fico ouvindo eles às vezes falar e fico pensando, bah, eles têm muito mais problemas que eu e eu não tenho problema nenhum, porque às vezes eles me consideram como brincalhão porque eu animo eles quando eles chegam de noite cansados, porque não é fácil e tô sempre aí. (Jovem D, homem, 20 anos).
\end{abstract}

A associação da fase jovem a determinada postura que contempla brincadeiras e extroversão, isto é, uma etapa marcada pelo dinamismo e pela criatividade (DEBERT, 2010) pode ser evidenciada na narrativa dos estudantes. Dessa forma, uma vida em constante movimento e com muitas atividades foi associada a uma postura que representa o universo jovem.

\footnotetext{
Ai... Se eu pudesse definir [jovem]... É não cair no comodismo, não parar, fazer uma coisa, por ser muito agitada também. [...] Porque a maioria casa, aquela rotina de... Entra numa rotina, casa, para de trabalhar ou trabalha em casa, chega o final de semana aquela mesma rotina e eu não. Eu desde que casei, a gente sempre tem uma festa, vamos sair pra jantar fora, vamos tomar um chimarrão numa praça, vamos na casa do fulano, vamos fazer um churrasco aqui, vamos viajar pra lá. (Jovem B, mulher, 24 anos).
} 
O fato de morar sozinho, conduzir sua vida sem consultar outras pessoas e ter responsabilidades nem sempre é tomado como condição suficiente para a vida adulta, sobretudo se houver dependência financeira. Embora o processo de transição para a vida adulta seja marcado por características como a complexidade e a heterogeneidade, a independência financeira é claramente um dos elementos que auxilia na demarcação da passagem para o mundo adulto. Isso, em geral, está associado também ao ingresso no mercado de trabalho, em especial, quando em condições que possibilitem uma autonomia financeira maior, principalmente no caso dos homens. Já em relação às mulheres, comumente a literatura apresenta que um marco maior para a adultícia é o casamento (CAMARANO; MELLO; KANSO, 2006).

Eu sou jovem adulto. [O que faz com que te classifique essa forma?] Não aceitar a idade que eu tenho e algumas atitudes ainda infantis que eu tenho. É eu saber que eu tenho uma idade suficiente pra me autossustentar e eu tenho que tomar decisões, mas nas financeiras eu preciso tomar mais decisões corretas. [...] [Então o adulto seria uma espécie de uma consciência de certo e errado em relação à tua vida?] É. Em relação às coisas que eu faço, às atitudes que eu tomo (Jovem E, homem, 23 anos).

O conjunto de relações das quais o indivíduo faz parte também pode ser um elemento que contribui para a classificação como jovem. O círculo de amizades, os colegas de trabalho, ou até mesmo os colegas de escola, podem exercer influência para que a pessoa consiga se compreender em determinada fase da vida, dado o tipo de comportamento desempenhado em cada uma dessas esferas.

[...] os meus amigos são sempre mais novos que eu, então eu tô sempre... Ao mesmo tempo que eu faço coisas, depois de um tempo eu vejo que foi uma coisa que eu não deveria ter feito (Jovem E, homem, 23 anos).

Ainda foi identificado um perfil de jovem estudante da EJA que, embora trabalhe, considera-se dependente da família, sobretudo para tomar decisões. Em alguma medida isso reflete uma situação em que, possivelmente, as responsabilidades assumidas pelo jovem ainda são restritas, o que é expresso por meio da ideia de ainda não ser suficientemente "maduro" para enfrentar as circunstâncias que a vida lhe impõe.

Como eu vou te dizer, não adulta ainda, mas também não adolescente. Jovem! Acho que eu não tô bem madura ainda como se diz os pais. Ah, tu não tá bem maduro. [...] Às vezes, eu acho que eu dependo dela [mãe] porque é onde eu trabalho (Jovem C, mulher, 20 anos).

Há uma expectativa de que a vida adulta será marcada pelo ingresso na faculdade e pelo alcance de uma profissão, sobretudo para aqueles entrevistados que 
apenas estudavam. Nesses casos, em geral, o jovem ainda está bastante ligado à família de origem e é dependente dela.

\begin{abstract}
Adolescente. [...] Porque eu sou meio braba, às vezes eu não consigo me controlar ainda. Um adulto tem um equilíbrio e eu ainda não atingi um equilíbrio. É eu acho que não vai mais existir em mim, eu acho que eu vou ser mais segura, acho que vou ter mais responsabilidade ainda. [...] Vai me ajudar sim, vou ter mais responsabilidade [com a faculdade e o trabalho], vou saber resolver os problemas com mais dinamismo, achar soluções diversas pras coisas, isso vai me ajudar a ficar adulta. Porque eu acho que eu podia tá me formando. O que eu acho é o seguinte, que os meus colegas [do período do Ensino Fundamental] sendo "mongolão" pra umas coisas, eles já são bem adultos pra outras, por causa da responsabilidade na escola, os horários, os trabalhos, se interessar pelas coisas, ser um bom aluno, entendeu. Acho que isso era uma parte deles bem mais evoluída que a minha, talvez eles não eram espertos para alguma coisa que eu era, mas eles eram responsáveis, eles estavam ali buscando o futuro deles (Jovem I, mulher, 18 anos).
\end{abstract}

A situação expressa pelo excerto anterior guarda consigo um caráter que reflete uma condição de classe. Embora a Jovem I já tenha trabalhado, isso não se colocou na sua trajetória de vida como uma necessidade para suprir condições básicas de sobrevivência como, por exemplo, no percurso de vida do Jovem A. A realidade de vida da Jovem I é caracterizada por uma situação econômica muito confortável, o que lhe possibilitou sempre estudar em escolas privadas e ter uma família com alto capital cultural, econômico e escolar. Isso significa que as condições econômicas exercem algum tipo de influência na forma como se a dá a autodefinição de jovem no que se refere à participação no mercado de trabalho.

\title{
6 Considerações finais
}

Em síntese, foram identificadas muitas perspectivas sobre o que pode compor a fase jovem e a adulta, de modo relacional. Isso esteve muito vinculado à forma como foram sendo constituídas as trajetórias de vida e as percepções que vão se desenvolvendo em cada universo. A transição para outra fase da vida é desenhada em idades e caminhos diferentes, da mesma forma que a vivência de cada etapa da vida ocorre também de maneiras distintas (PIMENTA, 2007).

A análise das trajetórias de vida permitiu identificar a perspectiva de que a vida adulta pode chegar com o trabalho e, nesse sentido, chegou muito cedo para alguns e, para outros, só chegará quando for alcançada a formação profissional que está no campo de desejo. Aqueles jovens que deixaram a escola para trabalhar ou que passaram a conciliá-la com o trabalho indicaram que se tornaram adultos naquele momento, 
sobretudo quando assumiram responsabilidades. No entanto, também podem ocorrer situações em que o trabalho veio apenas por uma vontade, para garantir maior independência, e não por uma necessidade, e isso ainda não é considerado o marco para o ingresso na vida adulta. A constituição de família foi indicada também como um marco para a vida adulta, mas não de modo absoluto, pois se pode evidenciar isso se constituindo de modos diferentes, conforme o percurso de vida.

A continuidade dos estudos dá um caráter de vida em formação, o que é associado pelos estudantes à fase jovem da vida. Atrelada a isso está também a realização de sonhos que foram deixados de lado ao longo da vida. Ter disposição para "correr atrás dos sonhos" remete a um "sentimento de jovialidade".

A presença na modalidade EJA pode fazer as pessoas se conceberem como mais jovens, visto que convivem com os jovens e ainda têm sonhos a serem alcançados. Por outro lado, esse ambiente pode tornar as pessoas mais adultas, por exemplo, no caso dos estudantes mais jovens, que convivem com colegas muito mais velhos e se sentem mais "maduros" em decorrência disso.

Há uma diversidade bastante significativa de posicionamentos em relação à definição de ser/sentir-se jovem, o que sofre variações tendo em vista as relações que são estabelecidas no decorrer das trajetórias de vida dos estudantes. Assim, percebe-se que a escolarização, a independência da família de origem e a aproximação com o mercado de trabalho, por exemplo, são marcos significativos para as fases do percurso de vida, conforme os próprios estudantes indicaram. Contudo, mesmo que o trabalho e a escolarização sejam significativos, eles não esgotam a questão, pois ainda é necessário considerar outros aspectos, como os estilos de vida e as maneiras diferenciadas de classificação que os próprios estudantes permitiram evidenciar.

Além disso, percebeu-se que os estudantes definem-se também de uma forma plural quanto ao ser jovem ou adultos, relacionando essas concepções com determinados momentos que enfrentam na vida.

\section{YOUTH AND ACADEMIC REINTEGRATION: MEANING OF BEING YOUNG}

Abstract: This study analyzes the representations that the students of EJA have about what it is to be young and how being in this modality of learning contributes to this. This analysis supports the understanding of the juvenile phenomenon of the EJA. Empirical data from quantitative-qualitative research are discussed that point to the 
significant presence of young people in the EJA/High School in the schools of Porto Alegre, and it is indicated the reason why these young people are in the EJA. The data are deepened with the analysis of the trajectory of students of the EJA. It discusses what it means to be young and to be studying the EJA and the perceptions of young people about this moment of life. Resuming studies refers to a sense of pathways under construction, which is associated with EJA students as a feature of youth.

Keywords: Youth, education, Youth and Adult Education, High School

\section{Referências}

ARIÈS, P. História social da criança e da família. Rio de Janeiro: Editora Guanabara, 1981.

BOURDIEU, P. Questões de sociologia. Lisboa: Fim de século, 2003.

BRUNEL, C. Jovens no ensino supletivo: reconstruindo trajetórias. 2001.210 f. Dissertação (Mestrado em Educação), Programa de Pós-Graduação em Educação, Universidade Federal do Rio Grande do Sul, Porto Alegre, 2001.

CAMARANO, A. A.; MELLO, J. L. Introdução. In.: CAMARANO, A. A. (Org.) Transição para a vida adulta ou vida adulta em transição? Rio de Janeiro: IPEA, 2006. p. 13-28.

CAMARANO, A. A.; MELLO, J. L.; KANSO, S. Do nascimento à morte: principais transições. In.: CAMARANO, A. A.. (Org.) Transição para a vida adulta ou vida adulta em transição? Rio de Janeiro: IPEA, 2006. p. 31-60.

CARMO, G. T. O enigma da Educação de Jovens e Adultos: um estudo das evasões e retornos à escola sob a perspectiva da teoria do reconhecimento social. 2010, $339 \mathrm{f}$. Tese (Doutorado em Sociologia Política), Programa de Pós-Graduação em Sociologia Política, Universidade Federal do Norte Fluminense, Campos dos Goytacazes, 2010.

CARRANO, P. Educação de Jovens e Adultos e Juventude: o desafio de compreender os sentidos da presença dos jovens na escola da "segunda chance". Revista de Educação de Jovens e Adultos, Belo Horizonte, v.1, p. 1-108, 2007.

DAYRELL, J. A escola "faz" as juventudes? Reflexões em torno da socialização juvenil. In: VIEIRA, M. M. Escola, jovens e media (Org.). Lisboa: Imprensa de Ciências Sociais, 2007. p. 191-229.

DAYRELL, J. O ensino médio no Brasil e seus desafios: o que dizem os jovens sobre o processo de exclusão escolar. Disponível em:

<http://www.automacaodeeventos.com.br/sigeventos/sbs2013/inscricao/resumos/0001/P DF_trab-aceito-3279-1.pdf> Acesso em: 14 jan. 2014.

DEBERT, G. G. A dissolução da vida adulta e a juventude como um valor. Horizontes Antropológicos, Porto Alegre, ano 16, n. 34, p.49-70, jun./dez. 2010. 
FERREIRA, V. S.; NUNES, C. Transições para a idade adulta. In.: PAIS, J. M.; FERREIRA, V. S. (ORGs.). Tempos e transições de vida: Portugal ao espelho da Europa. Lisboa: Imprensa de Ciências Sociais, 2010. p. 39-67.

DI PIERRO, M. C. Notas sobre a redefinição da identidade e das políticas públicas de educação de jovens e adultos no brasil. Educação e Sociedade, Campinas, v. 26, n. 92, p. 1115-1139, Especial - Out. 2005.

GIDDENS, A. As consequências da modernidade. São Paulo: Unesp, 1991.

GOUVEIA, D. S. M.; SILVA, A. M. T. B. da. A ampliação da faixa etária da EJA e o convívio intergeracional: pontos e contrapontos, LSP - Revista Científica

Interdisciplinar, Rio de Janeiro, v. 2, n. 3, jul.-set. 2015.

LAHIRE, B. Sucesso escolar nos meios populares: as razões do improvável. São Paulo: Ática, 1997.

MILETO, L. F. "No mesmo barco, dando força, um ajuda o outro a não desistir" - estratégias e trajetórias de permanência na Educação de Jovens e Adultos. 2009. 215 f. Dissertação (Mestrado em Educação). Programa de Pós-graduação em Educação, Universidade Federal Fluminense, Niterói, 2009.

NEVES, C. E. B. Trajetórias escolares, famílias e políticas de inclusão social no Ensino Superior brasileiro. In.: ROMANELLI, G.; NOGUEIRA, M. A.; ZAGO, N. (Org.).

Família \& Escola: novas perspectivas de análise. Petrópolis: Vozes, 2013. p. 278-311.

PAIS, J. M. A construção sociológica da juventude: alguns contributos. Análise Social, Lisboa, v. XXV, p. 139-165, 1990.

PAPPÁMIKAIL, L. A adolescência enquanto objecto sociológico: notas sobre um resgate. In.: PAIS, J. M.; BENDIT, R.; FERREIRA, V. S. (Orgs.) Jovens e rumos. Lisboa: Imprensa de Ciências Sociais, 2011. p. 81-99.

PERALVA, A. O jovem como modelo cultural. Revista Brasileira de Educação, Rio de Janeiro, n. 6, p. 15-24, set.-dez. 1997.

PEREIRA, A. B. Outros Ritmos em Escolas da Periferia de São Paulo. Educação \& Realidade, Porto Alegre, v. 41, n. 1, p. 217-237, jan./mar. 2016.

PIMENTA, M. M. "Ser jovem" e "ser adulto": identidades, representações e trajetórias. 2007. 464 f. Tese (Doutorado em Sociologia), Programa de Pós-Graduação em Sociologia, Universidade Federal de São Paulo, São Paulo, 2007.

SARAVÍ, G. A. Juventud y sentidos de pertenencia en América Latina: causas y riesgos de la fragmentación social. Revista Cepal, Santiago de Chile, n. 98, p. 47-65, ago. 2009. 
VANDENBERGHE, F. Globalização e individualização na modernidade tardia: uma introdução teórica à sociologia da juventude. Mediações, Londrina, v. 19, n. 1, p. 265316, jan.-jun. 2014. 